\title{
How Drug Use by French Elderly Patients Has Changed During the Last Decade
}

\author{
Jean-François Huon ${ }^{1}$ - Emilie Lenain ${ }^{2,3} \cdot$ Julien LeGuen $^{4,6}$ • Gilles Chatellier ${ }^{2,4}$ • \\ Brigitte Sabatier $^{1,5} \cdot$ Olivier Saint-Jean ${ }^{4,6}$
}

Published online: 9 October 2015

(c) The Author(s) 2015. This article is published with open access at Springerlink.com

\begin{abstract}
Background In France the most recent data on drug use by the elderly living at home were published in 2000 . Since then the available drugs and their use have changed.

Objective We compared data collected in 2011 with the 2000 data to evaluate how drug use has changed in France. Methods The study analysed retrospectively the 2011 data collected prospectively in France from a sample of 600,000 people representative (1/97th) of the French population. All prescribed drugs reimbursed by the French national health insurance were recorded. Due to the reimbursement procedure the unit of analysis was the trimester. The drugs were coded using the Anatomical Therapeutic Chemical (ATC) Classification System.
\end{abstract}

Electronic supplementary material The online version of this article (doi:10.1007/s40801-015-0041-6) contains supplementary material, which is available to authorized users.

\section{Julien LeGuen}

julien.leguen@egp.aphp.fr

$\bowtie$ Olivier Saint-Jean

olivier.saint-jean@egp.aphp.fr

1 Service Pharmacie, Hôpital Européen Georges-Pompidou, Paris, France

2 Assistance Publique-Hôpitaux de Paris, Hôpital European Georges-Pompidou, URC, Paris, France

3 INSERM, Centre d'Investigation Épidémiologique 4, Paris, France

4 Faculté de Médecine, Université Paris-Descartes, Sorbonne Paris Cité, Paris, France

5 INSERM UMR 872 Equipe 22, Centre de Recherche des Cordeliers, Paris, France

6 Service de Gériatrie, Hôpital Européen Georges Pompidou, 20 rue Leblanc, 75015 Paris, France
Results Data from 580,989 patients were analysed $(133,411 \quad(23.0 \%)$ aged $\geq 60$ years, 32,314 (5.6\%) $\geq 80$ years). The percentage of patients who used medication increased from $55.9 \%$ for patients in their fourth decade to $88.6 \%$ for patients in their eighth decade, remained stable till 90 years of age and decreased to $26.3 \%$ in centenarians. The median number of drugs prescribed was five (IQR: 3-8) in those aged under 80 years and ten (IQR: 7-14) in those aged over 80 years. Cardiovascular drugs were the most used, by $70.9,78.1$, and $69.6 \%$ of patients aged 70-79, 80-89, and 90-99 years, respectively. Analgesics, non-steroidal anti-inflammatory drugs, and antibiotics were prescribed in almost half of the patients.

Conclusion Polypharmacy is common among the elderly in France. Although this may be explained by the multiple co-morbidities, our results suggest an overuse of drugs for which the risk-benefit ratio is unknown in these age ranges. Consequently, numerous elderly patients are exposed to iatrogenic risks without the certainty of therapeutic benefits.

\section{Key Points}

The percentage of medication users in France increases with age, with almost $90 \%$ of octogenarians receiving drug therapy.

The number of drugs used also increases with age, with patients over the age of 80 years receiving a median of ten drugs.

This elderly population may be exposed to a high risk of adverse drug reactions resulting from polypharmacy. 


\section{Introduction}

According to the Organisation for Economic Co-operation and Development, France had one of the highest pharmaceutical expenditures in the world in 2001 [1], which has risen more than $50 \%$ in the past decade [2], the elderly being the greatest consumers [3]. State of health is the main determinant of the use of pharmaceuticals among the elderly and multiple illnesses logically lead to polypharmacy, defined as the use of multiple medications and/or more medications than are clinically indicated [4-6] and to increased drug use as health declines [7].

We examined the state of drug use among the elderly in France and how it has changed in recent years. The most recent data on elderly French people living at home were published in 2000 by the Institut de Recherche et Documentation en Economie de la Santé (IRDES; Institute for Research and Information in Health Economics). Over the last decade, the French population has increased and with it the consumption of drugs [8]. The availability of drugs has also changed as some of them have been withdrawn or delisted, and new drugs have became available on the market. Lastly, guidelines for good geriatric clinical practice have been published (e.g., [9-11]). By updating the data on drug use by the elderly and comparing them with the most recent published data, the aim of this study was to provide information for the authorities involved in elderly care in order to adapt the future health strategies appropriately.

\section{Methods}

\subsection{Source Data, Population and Experimental Plan}

We retrospectively analysed the EGB sample (Echantillon Généraliste de Bénéficiaires), which is representative of French health insurance beneficiaries, data on whom are collected prospectively by the public health insurance authority (Assurance Maladie). The EGB is a representative and anonymous sample of beneficiaries of the three main French health insurance schemes, which ensures approximately $86 \%$ representativity of the French population [12,13]. It results from a 1/97th sampling of beneficiaries, whether or not they have been reimbursed for medical expenses (drugs included). It currently includes nearly 670,000 people. This database includes sociodemographic information on beneficiaries plus data on reimbursement of their medical expenses. The population living in nursing homes is excluded.

All EGB cohort members present throughout 2011 were selected for the study. They were considered medical-care consumers if they had been reimbursed for the purchase of prescribed drugs at least once in the year.

\subsection{Classification of Drugs}

All drugs purchased during 2011 were included. In the EGB cohort, reimbursed drugs were coded using the Anatomical Therapeutic Chemical (ATC) Classification System, which divides drugs into different groups according to the organ or system on which they act and/or their therapeutic and chemical characteristics. In France nearly 3,000 active substances are included in the composition of medicinal products. We therefore decided to divide them into 74 clinically relevant classes, starting from the ATC sections and highlighting some drugs or family of drugs. This methodological choice was made by a working group comprising a clinician (OSJ), two pharmacists (JFH and BS) and a statistician (EL). We made a consensus decision when there were differing views. For example, we divided analgesics into three distinct classes: paracetamol, opioid drugs and other analgesics, or we selected the ATC family 'cardiovascular system' but chose to highlight statins or diuretics in addition.

These 74 classes were then divided into ten large classes so as to summarise the results in a clinically meaningful manner from a geriatric viewpoint (cardiovascular and related drugs, drugs for degenerative diseases, vaccines and antibiotics, psychoactive drugs, diabetes drugs, anti-ulcer agents, nonsteroidal anti-inflammatory drugs (NSAIDs) and drugs for rheumatological diseases and the musculoskeletal system, analgesics, drugs for the respiratory system, drugs for thyroid disorders). This first division in 74 classes was made to have more precise data about interesting medicines or drug families (see supplementary material). It would have been impossible to get a clear and clinically significant synthesis if we had kept these 74 classes, so they were clustered in ten large classes that the multidisciplinary group deemed to be clinically interesting from a geriatric viewpoint. That is why, for example, NSAIDs are grouped separately, because of the serious side effects they produce, particularly in the elderly. Drugs fitting none of these categories were classed as 'Other'.

\subsection{Qualitative Analyses}

The population was analysed in 10-year age ranges and we focused on people aged 65 years and over. The percentage of drug users and the number of drugs reimbursed were calculated for 3-month periods to take account of medication that can be prescribed for 3 months. A sensitivity analysis comparing these two results for the four quarters of 2011 revealed stable use during the year, except for vaccines, use of which was seasonal because of the influenza immunization programme, and antibiotics, due to the greater frequency of respiratory problems during winter. It 
was decided to present the results for the fourth quarter of the year.

The number of drugs corresponded to the number of different active substances reimbursed by the French health insurance system. Thus, a prescription for two identical drugs or for different dosages of the same drug was only taken into account once for a given cohort member. Conversely, a combination therapy was considered as including two distinct drugs. Only the drug users were considered in the analysis of the number of drugs.

\section{Results}

\subsection{Characteristics of the Population}

In 2011, 594,317 beneficiaries were covered by at least one of the three main insurance schemes included in the EGB cohort. Of them, $1.5 \%(9,039)$ were lost to follow-up (switched to another health insurance scheme) and $0.7 \%$ $(4,289)$ died during that year. Drug use was analysed in 580,989 people $(50.7 \%$ women; mean age $40.1 \pm 23.7$ years). Of cohort members, $16.9 \%(98,052)$ were over 65 years of age, $5.6 \%(32,314)$ were over 80 years of age and 541 were centenarians.

\subsection{Overall Active Drugs}

The percentage of cohort members who used medicinal products at least once in the year (Fig. 1) varied according to age: from 10 to 80 years, it rose linearly from 51.5 to $88.6 \%$, then levelled off, and declined sharply to $26.3 \%$ among centenarians. The greatest use of medicinal products was seen among the 70- to 89-year-olds.

As with the percentage of drug users, the number of active substances reimbursed increased with age (Fig. 1), from 3.2 drugs at 10-19 years to 9.2 drugs between 80 and 99 years of age. Only $14 \%$ of drug users aged 65 years or more were reimbursed for fewer than four drugs for the 3-month period and over $25 \%$ of them used more than 12 different drugs.

\subsection{Drug Use by Class}

In people aged 65 years and over, $21 \%$ of drugs reimbursed were for cardiovascular conditions (Fig. 2). Cardiovascular drugs were used the most, by $70.9,78.1$ and $69.6 \%$ of patients aged $70-79,80-89$ and $90-99$ years, respectively. Analgesics were used by $36-51 \%$ of elderly drug users, depending on age class. Vaccines and antibiotics were also widely used (32-52\% of drug users). From 11 to $45 \%$ of the elderly used NSAIDs or drugs for rheumatological and bone diseases, which reflects the prevalence of musculoskeletal disorders (e.g. osteoarthritis, osteoporosis) in older people. Psychoactive drugs were used by $14 \%$ of centenarians and $43 \%$ of nonagenarians. Anti-ulcer drugs, mostly proton pump inhibitors, were used by $26 \%$ of the elderly ( $10 \%$ of centenarians and $32 \%$ of octogenarians).

\subsection{Comparison with 2000 Data}

Comparing our 2011 findings (Table 1) with data from the 2000 CREDES/IRDES health and social protection survey (ESPS), it was found that analgesics, notably paracetamol, remained in first place among the drugs most used by the elderly. The 2000 CREDES/IRDES results, presented in terms of brand drugs, placed Di-Antalvic (paracetamol plus dextropropoxyphene), Doliprane, Dafalgan and Efferalgan (paracetamol alone) in first, third, fifth and sixth positions, respectively. Ten years on, paracetamol was still in first place. Dextropropoxyphene, the major ingredient of $\mathrm{Di}$ Antalvic and Di-Algirex (18th place in 2000), was
Fig. 1 Percentage of cohort members (dotted line) who bought a drug and the number of drugs (solid line) bought (Echantillon Généraliste de Bénéficiaires [13], fourth quarter of 2011), according to age

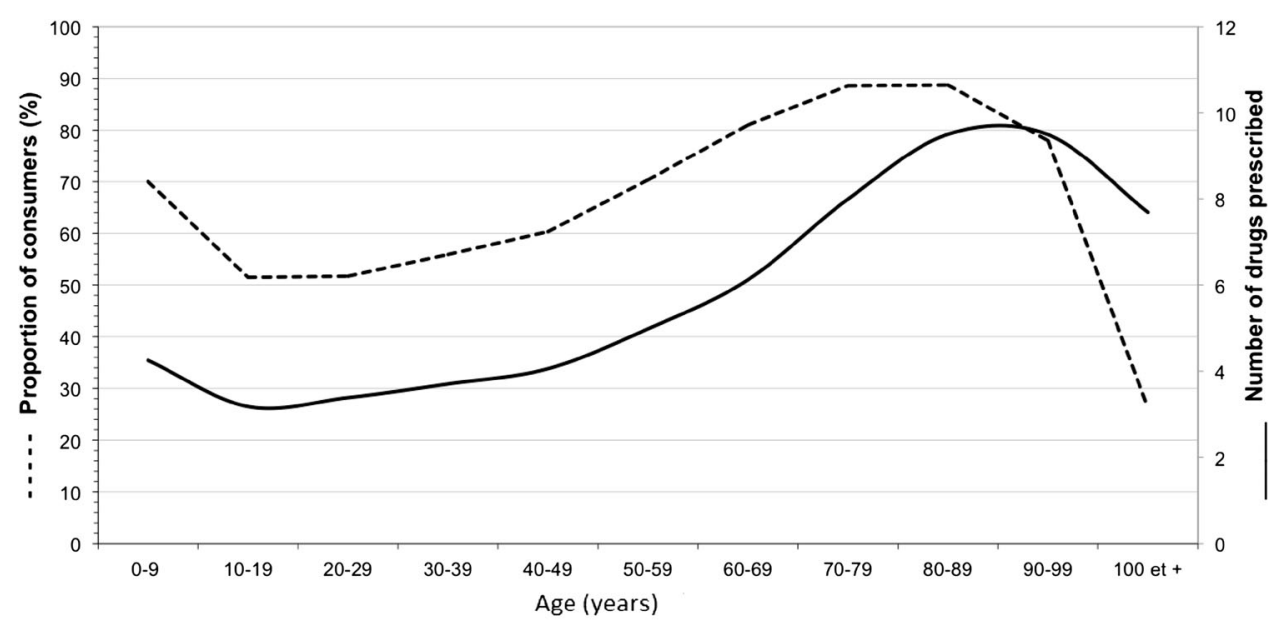

(*) EGB : Echantillon Généralistes des Bénéficiaires [13] 
Fig. 2 Proportion of consumers by age range and drug class

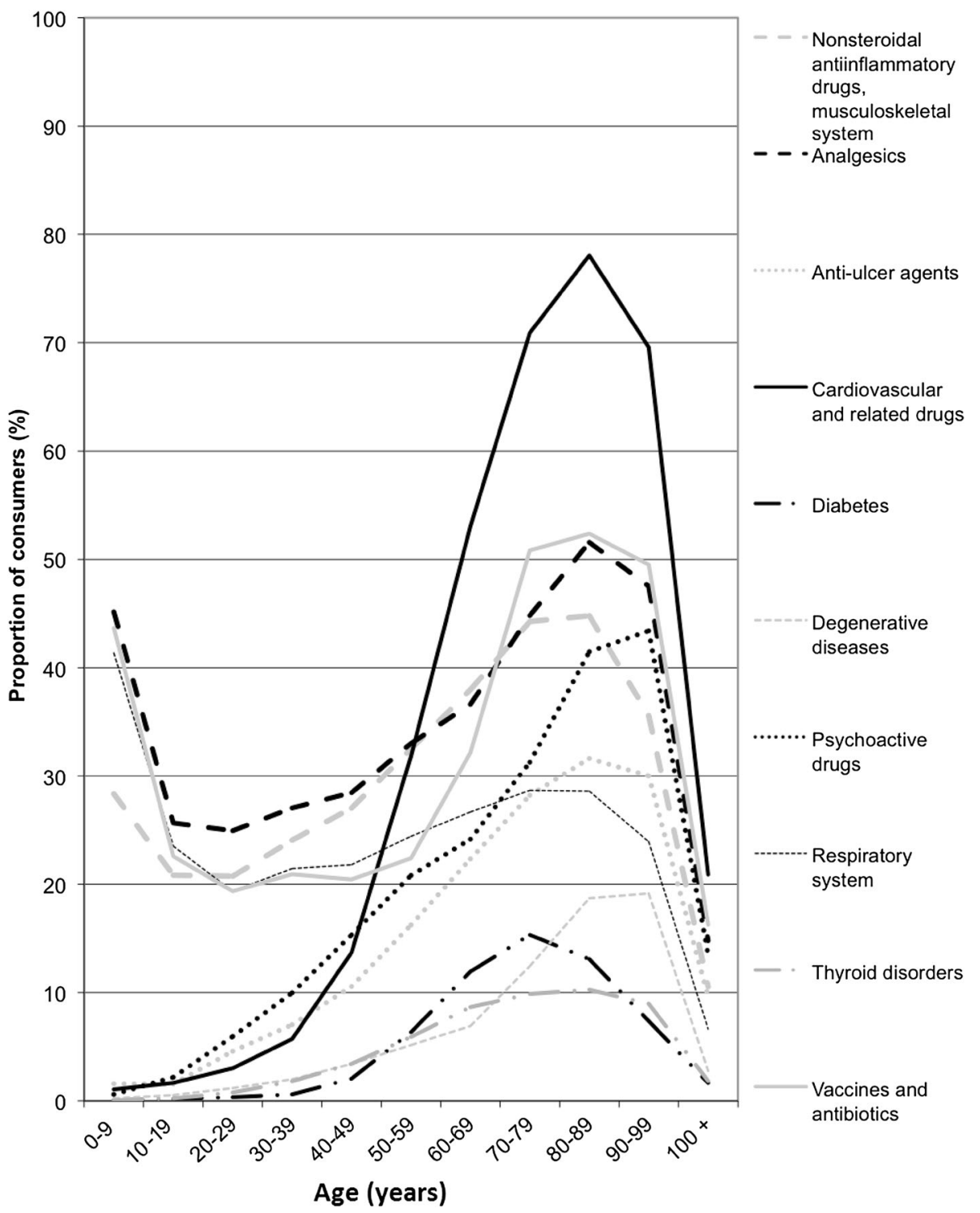

withdrawn in 2009 and tramadol climbed to 15 th place. Twelve drugs, delisted or withdrawn, had disappeared from the new classification.

\section{Discussion}

Our study shows that the percentage of drug use in the EGB cohort increased from age 30 to age 65 years, peaked at $90 \%$ among octogenarians, and then declined, with a sharp drop among centenarians. The curve of percentage use was superimposable on the number of drugs reimbursed per person over the year, which increased from 3.2 drugs from 10-19 years of age to 9.2 drugs in octogenarians and nonagenarians before decreasing to 7.9 drugs among centenarians. The three large classes of most prescribed drugs in those aged 65 years or over were cardiovascular (64\% of drug users), analgesics (42\%) and vaccines and antibiotics (42\%). Psychoactive drugs were also widely used $(31 \%)$.

Quantitatively, our findings are similar to those published 10 years ago. The disappearance of some drugs from the 2011 classification is explained by the fact that the French national health authority (Haute Autorité de Santé) delisted certain drugs, the therapeutic benefit of which was deemed insufficient $[14,15]$. The health authority also followed the recommendations of the European Medicines Agency in 2009 on the progressive discussions withdrawal in Europe of certain drugs that carry risks in the event of overdosage [16].

Cardiovascular drugs such as platelet inhibitors, diuretics, agents acting on the renin-angiotensin system, betablockers and statins were more common in the 2011 classification, with 17 of the 30 most used drugs, compared with ten in 2000 . This could be explained by the spread of 
Table 1 Comparison of the 30 most sold drugs among thoseaged over 65 years: 2000 vs. 2011

\begin{tabular}{|c|c|c|c|}
\hline Rank & $\begin{array}{l}2000 \text { (CREDES, ESPS survey) } \\
\text { Commercial name (DCI) }\end{array}$ & Rank & $\begin{array}{l}2011(\text { EGB }) \\
\text { DCI }\end{array}$ \\
\hline 1 & \# Di-Antalvic ${ }^{\circledR}$ (dextropropoxyphene, paracetamol) & 1 & Paracetamol \\
\hline 2 & Kardégic $^{\circledR}$ (acetylsalicylic acid) & 2 & Acetylsalicylic acid \\
\hline 3 & Doliprane $^{\circledR}$ (paracetamol) & 3 & Hydrochlorothiazide \\
\hline 4 & \# Vastarel ${ }^{\circledR}$ (trimetazidine) & 4 & Sodium levothyroxin \\
\hline 5 & Dafalgan $^{\circledR}$ (paracetamol) & 5 & Furosemide \\
\hline 6 & \# Efferalgan ${ }^{\circledR}$ (paracetamol) & 6 & Influenza vaccine \\
\hline 7 & \# Tanakan ${ }^{\circledR}$ (ginkgo biloba extract) & 7 & Metformin \\
\hline 8 & \# Endotélon ${ }^{\circledR}$ (grapeseed extract) & 8 & Bisoprolol \\
\hline 9 & \# Fonzylane ${ }^{\circledR}$ (buflomedil) & 9 & Atorvastatin \\
\hline 10 & \# Gaviscon ${ }^{\circledR}$ (sodium alginate) & 10 & Colecalciferol \\
\hline 11 & Stilnox $^{\circledR}$ (zolpidem tartrate) & 11 & Clopidogrel \\
\hline 12 & Corvasal $^{\circledR}$ (molsidomine) & 12 & Diclofenac \\
\hline 13 & Lasilix $^{\circledR}$ (furosemide) & 13 & Omeprazole \\
\hline 14 & Amlor $^{\circledR}$ (amlodipine) & 14 & Amlodipine \\
\hline 15 & \# Daflon ${ }^{\circledR}$ (flavonoïc) & 15 & Tramadol \\
\hline 16 & Aspégic $^{\circledR}$ (acetylsalicylic acid) & 16 & Simvastatin \\
\hline 17 & Mopral $^{\circledR}$ (omeprazole) & 17 & Rosuvastatin \\
\hline 18 & \# Dialgirex ${ }^{\circledR}$ (dextropropoxyphene, paracetamol) & 18 & Calcium in combination \\
\hline 19 & Zocor $^{\circledR}$ (simvastatin) & 19 & Perindopril \\
\hline 20 & Previscan ${ }^{\circledR}$ (fluendione) & 20 & Allopurinol \\
\hline 21 & Zyloric $^{\circledR}$ (allopurinol) & 21 & Pravastatin \\
\hline 22 & \# Praxilène ${ }^{\circledR}$ (naftudrofuryl) & 22 & Influenza antigen vaccine \\
\hline 23 & \# Veinamitol ${ }^{\circledR}$ (troxerutine) & 23 & Valsartan \\
\hline 24 & Diamicron $^{\circledR}$ (glyclazide) & 24 & Vitamin $\mathrm{K}$ antagonist \\
\hline 25 & Sotalex ${ }^{\circledR}$ (sotalol) & 25 & Irbesartan \\
\hline 26 & Cozaar $^{\circledR}($ losartan $)$ & 26 & Pantoprazole \\
\hline 27 & Sectral $^{\circledR}$ (acebutolol) & 27 & Lercanidipine \\
\hline 28 & \# Piasclédine ${ }^{\circledR}$ (soybean extract) & 28 & Fenofibrate \\
\hline 29 & Lipanthyl $^{\circledR}$ (fenofibrate) & 29 & Esomeprazole \\
\hline 30 & Témesta ${ }^{\circledR}$ (lorazepam) & 30 & Candesartan \\
\hline
\end{tabular}

\# Withdrawn or delisted

CREDES = Centre de Recherche d'Étude et de Documentation en Économie de la Santé, DCI = Dénomination Commune Internationale, EGB $=$ Echantillon Generaliste de Beneficiaires, EsPs $=$ IRDES health and social protection survey, IRDES = institute for research and information in health economics recommendations concerning care of cardiovascular diseases [17]. The widespread use of the influenza vaccine is due to the methodological choice to consider the fourth quarter of the year, during which the influenza immunisation programme takes place. This frequent use of influenza vaccines shows that the elderly population is now highly vaccinated, in line with the recommendations of the French Public Health Council (Haut Conseil de la Santé Publique). Proton pump inhibitors are still widely used.

The efficacy of the drugs used in 2011 has been validated by the health authorities according to strict criteria, which was not the case in 2000 when some marketed drugs were of uncertain efficacy. However, this recognised efficacy is based on studies including few if any very elderly subjects, so there is some doubt regarding drug efficacy and riskbenefit ratio in such patients. However, studies with population-based cohorts of patients are published and will outline tolerance and treatment efficacy (e.g. [18]).

The literature shows that in France those aged 65 years or over in 2000 used on average three to five different drugs a day, with those aged 80 years or over using 4.4 [19], as reported in other studies $[20,21]$. The updated data from our study, the methodology of which differed as it was not a survey, highlight a substantial increase over the last 10 years. This is a limitation of our study. In 2011, 70- to 79-year-olds used on average between six and seven different drugs, and those aged over 80 years used more than eight. The number of active substances used by the elderly has therefore virtually doubled in the last 
10 years. This rise in drug use with age, characterised 20 years ago as 'relatively recent' [22], has become more pronounced over the last decade.

Studies from other countries report similar findings. In Sweden in 2011, octogenarians used 5.3 drugs per person, nonagenarians 5.7, and centenarians 5.1 [23], showing a reduction in the very elderly. In a 2010 Polish study [24], $12 \%$ of centenarians used at least one drug, not far from the $20 \%$ of French centenarians. However, the average number of prescribed drugs in this population in Poland was $1.9( \pm 2.2)$ as it reached seven on average in France.

The first results of a comparative study of drug sales in seven European countries between 2000 and 2011 [25] show that France, once the country that consumed the most anti-ulcer drugs, antibiotics, antidepressants, anxiolytics, drugs for asthma, hypertension and diabetes, and lipid-lowering drugs, is now around the European average (except for antibiotics and anxiolytics, where France is still the leading consumer). This convergence between countries from 2000 to 2011 is due to the fact that over this period the countries with the generally highest growth in drug use were those whose sales levels in 2000 were the lowest (UK, Germany and Italy). The reasons for this increased use in Europe have not been analysed, but national public health programmes play a part [26].

In our study, the observed tendency to decreased drug use in the very elderly is paradoxical and hard to explain. One hypothesis is that the number of people with multiple morbidities decreases as the population ages: the sickest old people die and the survivors are relatively healthier and take fewer drugs. Another hypothesis is that an increase in iatrogenic complications results in the death of those patients taking the most drugs. Lastly, it could be that the oldest and therefore sickest patients, who are the greatest users of medicinal products, are institutionalised and so excluded from the sample analysed.

The EGB cohort is representative of the population covered by the three main French health insurance systems and therefore does not include those on minority or supplementary insurance schemes. In addition, nursing home patients are excluded. This can easily explain the decrease in drug use above 95 years of age, as more than $50 \%$ of those aged over 95 years are institutionalised. Moreover, neither self-medication nor the taking of prescribed drugs that are not reimbursed can be measured. Conversely, the fact that a medication is purchased and reimbursed does not necessarily mean that it is taken by the patient [27].

\section{Conclusion}

Our study shows that drug use by the elderly in France has evolved over the last 10 years. Already among the highest in Europe and the world, it shows no sign of abating, whereas life expectancy in good health is levelling off. As the number of sick people increases, so too does the need for medication. This polypharmacy, which is justified by the large number of symptoms and diseases affecting the elderly, raises the problem of adverse drug reactions, complex and unpredictable interactions, and the adaptation of clinical recommendations to geriatric patients. The elderly are particularly exposed to iatrogenic effects, most of which involve cardiovascular drugs and psychoactive drugs. Our study also shows that the drug classes most used are influenced by delisting and by public health policy recommendations. The results of this study were communicated to the French Health Ministry in April 2015.

Acknowledgments The authors thank the CNAM-TS for making data from the EGB cohort freely available.

Author contributions JFH: study concept, analysis and preparation of paper

EL: methods and analysis

JL: study concept and preparation of paper

BS: study concept, analysis and preparation of paper

GC: study concept, analysis and preparation of paper

OSJ: study concept, analysis and preparation of paper

\section{Compliance with Ethical Standards}

Funding This study received no funding.

Conflict of interest JFH, EL, JL, GC, BS and OSJ report that they have no conflicts of interest to declare.

Ethical approval Ethical approval was not required.

Open Access This article is distributed under the terms of the Creative Commons Attribution-NonCommercial 4.0 International License (http://creativecommons.org/licenses/by-nc/4.0/), which permits any noncommercial use, distribution, and reproduction in any medium, provided you give appropriate credit to the original author(s) and the source, provide a link to the Creative Commons license, and indicate if changes were made.

\section{References}

1. Organisation for Economic Co-operation and Development (OECD). Health at a Glance: Europe 2003 [Internet]. 2003. Available from: http://www.oecd-ilibrary.org/social-issuesmigration-health/health-at-a-glance-2003_health_glance-2003-en. Cited 26 May 2015.

2. Organisation for Economic Co-operation and Development (OECD). Health at a Glance: Europe 2014 [Internet]. 2014. Available from: http://www.oecd.org/health/health-at-a-glanceeurope-23056088.htm. Cited 26 May 2015.

3. Haut Conseil pour l'Avenir de l'Assurance Maladie. Rapport du Haut Conseil pour l'Avenir de l'Assurance Maladie; 2006.

4. Hajjar ER, Cafiero AC, Hanlon JT. Polypharmacy in elderly patients. Am J Geriatr Pharmacother. 2007;5(4):345-51.

5. Shalini M, Joshi M. Study of polypharmacy and associated problems among elderly patients. Internet $\mathrm{J}$ Med Update. 2012;7:35-9. 
6. Patterson SM, Hughes C, Kerse N, Cardwell CR, Bradley MC. Interventions to improve the appropriate use of polypharmacy for older people. Cochrane Database Syst Rev. 2012;5:CD008165.

7. Auvray L, Dumesnil S, Le Fur P, Centre de Recherche d'Etude et de Documentation en Economie de la Santé. Santé, soins et protection sociale en 2000. 2001. https://www.google.fr/ search?q=Auvray $+\mathrm{L},+$ Dumesnil $+\mathrm{S},+\mathrm{Le}+\mathrm{Fur}+\mathrm{P},+$ Centre + de + Recherche $+\mathrm{d} \%$ E2\% 80\%99Etude $+\mathrm{et}+\mathrm{de}+$ Documentation + en + Economie + de + la + Sant $\%$ C3\%A9. + Sant $\%$ C3\%A9, +soins + et + protection + sociale + en $+2000 .+2001 \mathrm{~S} \&$ ie $=$ utf $-8 \&$ oe $=u t f-$ 8\&gws_rd=cr\&ei=TzoSVv7CJsP6ygPG5LvQAQ\#q=Auvray+ $\mathrm{L} \% 2 \mathrm{C}+$ Dumesnil $+\mathrm{S} \% 2 \mathrm{C}+\mathrm{Le}+\mathrm{Fur}+\mathrm{P} \% 2 \mathrm{C}+\mathrm{Centre}+\mathrm{de}+\mathrm{Re}$ cherche $+\mathrm{d} \% \mathrm{E} 2 \% 80 \% 99 \mathrm{Etude}+\mathrm{et}+\mathrm{de}+$ Documentation $+\mathrm{en}+$ Economie $+\mathrm{de}+\mathrm{la}+$ Sant $\% \mathrm{C} 3 \%$ A9. + Sant $\% \mathrm{C} 3 \%$ A9\%2C + soins + et + protection+sociale + en $+2000 .+2001$. Accessed 5 Oct 2015.

8. LEEM. Bilan économique des entreprises du médicament-édition 2014 [Internet]. 2014. Available from: http://www.leem.org/ bilan-economique-des-entreprises-du-medicament-edition-2014. Cited 27 May 2015.

9. Fick DM, Semla TP. 2012 american geriatrics society beers criteria: new year, new criteria, new perspective. J Am Geriatr Soc. 2012;60(4):614-5.

10. Haute Autorité de Santé. Modalités d'arrêt des benzodiazépines et médicaments apparentés chez le patient âgé [Internet]. 2007. Available from: http://www.has-sante.fr/portail/upload/docs/ application/pdf/arret_des_bzd_-_argumentaire.pdf. Cited 27 May 2015.

11. Haute Autorité de Santé. Prise en charge de la maladie d'Alzheimer et des maladies apparentées: interventions médicamenteuses et non médicamenteuses [Internet]. Available from: http://www.omedit-hautenormandie.fr/Files/maladie_dalzheimer synthese___interventions_medicamenteuses_et_non_medica menteuses.pdf. Cited 27 May 2015.

12. Assurance Maladie. L'échantillon généraliste de bénéficiaire [Internet]. 2009. Available from: http://www.ameli.fr/l-assurancemaladie/statistiques-et-publications/points-de-repere/n-25-1-echan tillon-generaliste-de-beneficiaires.php. Cited 28 Nov 2012.

13. Roquefeuil LD, Studer A, Neumann A, Merlière Y. L'échantillon généraliste de bénéficiaires: représentativité, portée, et limites. Pratiques et Organisation des Soins. 2009;40(3):213-23.

14. Haute Autorité de Santé. Réévaluation du Service Médical Rendu (SMR) - 1991-2001 [Internet]. 2001. Available from: http://www. has-sante.fr/portail/jcms/c_451925/reevaluation-du-service-medicalrendu-smr-1999-2001?xtmc=\&xtcr=33. Accessed 5 Oct 2015.

15. Ministère du travail, de l'emploi et de la santé, Journal Officiel de la République. Arrêté du 24 janvier 2012 portant radiation de spécialités pharmaceutiques de la liste mentionnée au premier alinéa de l'article L. 162-17 du code de la sécurité sociale. 2012.
http://www.legifrance.gouv.fr/eli/arrete/2012/1/24/ETSS1129357A/ jo/texte/fr. Accessed 5 Oct 2015.

16. European Medicines Agency. European Medicines Agency recommends withdrawal of dextropropoxyphene-containing medicines [Internet]. 2009. Available from: http://www.emea. europa.eu/. Cited 14 Apr 2013.

17. Haute Autorité de Santé. Prévention vasculaire après un infarctus cérébral ou un accident ischémique transitoire [Internet]. 2008. Available from: http://www.has-sante.fr/portail/jcms/c_1252051/ fr/prevention-vasculaire-apres-un-infarctus-cerebral-ou-un-accidentischemique-transitoire. Accessed 5 Oct 2015.

18. Joppi R, Cinconze E, Mezzalira L, Pase D, Poggiani C, Rossi E, et al. Hospitalized patients with atrial fibrillation compared to those included in recent trials on novel oral anticoagulants: a population-based study. Eur J Intern Med. 2013;24(4):318-23.

19. Auvray L, Sermet C. Consommations et prescriptions pharmaceutiques chez les personnes âgées-Un état des lieux. Gérontologie et Société. 2002;4(103):13-27.

20. Union Régionale des Caisses d'Assurance Maladie de HauteNormandie et Union Régionale des Médecins libéraux. Personnes âgées et médicaments. 2002. http://www.bdsp.ehesp.fr/Base/ 260836/. Accessed 5 Oct 2015.

21. Salles-Montaudon N, Fourrier A, Dartigues JF, Rainfray M, Emeriau JP. Evolution of drug treatments in the aged living at home. Rev Méd Intern. 2000;21(8):664-71.

22. Lecomte T, Centre de Recherche, d'Etudes et de Documentation en Economie de la Santé. La consommation pharmaceutique en 1991. 1994. http://www.bdsp.ehesp.fr/Base/88339/. Accessed 5 Oct 2015.

23. Wastesson J, Parker M, Fastbom J, Thorslund M, Johnell K. Drug use in centenerians compared with nonagenarians and octogenarians in Sweden: a nationwide register-based study. Age Ageing. 2011;2012(41):218-24.

24. Rajska-Neumann A, Mossakowska M, Wieczorowska K. Drug consumption among Polish centenarians. Arch Gerontol Geriatrics. 2011;53:29-32.

25. LIR-ESSEC. Evolution comparée des ventes de médicaments dans 7 pays européens (2000-2011). 2012. http://www.lir.asso.fr/. Accessed 5 Oct 2015.

26. The Dartmouth Institute for Health Policy and Clincal Practice. The Dartmouth Atlas of Medicare Prescription Drug Use. 2013. http://www.dartmouthatlas.org/publications/reports.aspx. Accessed 5 Oct 2015.

27. Observatoire Régional de la Santé Franche Comté, URCAM Franche Comté. L'automédication et l'observance thérapeutique chez les personnes âgées de plus de 70 ans. 2003. http://www. bdsp.ehesp.fr/Base/304961/. Accessed 5 Oct 2015. 